\title{
BENZOYL PEROXIDE DECOMPOSITION BY NITROGEN-CONTAINING CARBON NANOMATERIALS
}

\author{
Daryna Haliarnik ${ }^{\mathrm{a}}$, Oleg Petuhov ${ }^{\mathrm{b}}$, Olga Bakalinska ${ }^{\mathrm{a}^{*}}$, Tudor Lupascu ${ }^{\mathrm{b}}$, Mykola Kartel ${ }^{\mathrm{a}}$ \\ ${ }^{a}$ Chuiko Institute of Surface Chemistry, National Academy of Sciences of Ukraine, 17, General Naumov Str., Kyiv 03164, Ukraine \\ ${ }^{b}$ Institute of Chemistry of Academy of Sciences of Moldova, 3, Academiei str., Chisinau MD-2028, Republic of Moldova \\ *e-mail: bakalin2008@ukr.net; phone: (+38044) 42296 02; fax: (+38 044) 4249464
}

\begin{abstract}
In this paper the determination of catalytic activities of nanoporous KAU and SKN carbon materials, as well as catalytic activities of their modified (oxygen- and nitrogen-containing) forms and of enzyme catalase by calculating the Michaelis constants according to the kinetics of substrate decomposition has been reported. It has been shown that nitrogen-containing materials provide the highest catalytic activity in non-aqueous media, while the activity of catalase in non-aqueous media is small. It has been established that the catalytic activity of the samples does not correlate with structural parameters but depends on the change of their surface chemistry. The catalytic activity is decreased by the addition of oxygen atoms and, vice-versa, is increased by addition of nitrogen atoms. It has been found that the catalytic activity of studied samples correlates with surface basicity as well as the presence of quaternary nitrogen in the chemical structure.
\end{abstract}

Keywords: carbon nanomaterials, activated carbon, benzoyl peroxide, catalytic activity, Michaelis constant.

Received: March 2016/ Revised final: May 2016/Accepted: May 2016

\section{Introduction}

Recent increase in the number of enterprises of chemical, pharmaceutical, metallurgical and food industry leads to a continuous environmental pollution with harmful organic and inorganic substances. Mankind is in a continuous search to solve this problem. Due to high surface area, nanoporous carbon materials (NCM) are used as absorbers in sorption technologies and catalysts supports for water and air purification from harmful organic substances [1]. Activated carbon (AC) ranks first among these materials because of a number of its advantages: it is a cost-effective, affordable and not specific sorbent, while the possibility of significant variation of parameters increases its applicability. Activated carbon is a widely used adsorbent for air purification from harmful gases, such as $\mathrm{SO}_{2}, \mathrm{CO}_{2}$ [2] and it is also used as a catalyst for the oxidation of $\mathrm{SO}_{2}$ to $\mathrm{SO}_{3}[3]$. $\mathrm{AC}$ is known to be also used for wastewater treatment from heavy metals and their compounds ( $\mathrm{Cr}(\mathrm{VI}), \mathrm{Cu}(\mathrm{II}), \mathrm{Ni}(\mathrm{II}), \mathrm{Pb}(\mathrm{II}), \mathrm{Hg}$ [4-6]), from organic compounds (diphenyl, phenol and chlorinated organic compounds [7-9]).

Pollution by pharmaceutical products, such as tetracycline, a residue of veterinary drugs found in wastewater, as well as in drinking water, has been reported [10]. Wastewater may be purified by adsorption of tetracycline by carbon nanotubes [10]. Nowadays, carbon nanotubes become promising materials for replacing AC adsorbents in water purification from organic pollutants.

$\mathrm{NCM}$ can also be used as catalysts in heterogeneous catalysis. In particular, AC is used as a catalyst in reactions of halogenation, organic compounds decomposition, oxidation-reduction, dehydrogenation etc. [11]. These properties of $\mathrm{AC}$ are suitable for drinking water purification from organic pollutants as well as for wastewater treatment.

In this paper the study regarding the catalytic activity of carbon nanoporous materials with different contents of heteroatoms in a model reaction of benzoyl peroxide decomposition in non-aqueous media is presented. This investigation has been resulted in establishing correlations between the structure of the carbon matrix, modification of their surface chemistry and the catalytic activity.

\section{Experimental Materials}

In this study two series of nanoporous carbon materials have been used: i) nitrogen-containing active carbon SKN (obtained from nitrogen-containing precursor vinylpyridine resin) and its modified forms - SKNo (oxidized with nitric acid) and N-SKN (nitrogen-enriched, obtained by urea impregnation followed by the heat treatment [12]); ii) active carbon KAU (obtained from the shells of apricot stones) and its modified forms - KAUo (oxidized with nitric acid), nitrogen-containing N-KAU (obtained by urea impregnation followed by the heat treatment [12]) and KAUo- $\mathrm{NH}_{2}$ (oxidized KAUo chemically modified with 1,5-pentanediamine).

Enzyme catalase (from bovine liver, K 1.11.1.6, activity 329300 a.u.) was purchased from Fluka, powdered benzoyl peroxide (contained $25 \%$ water) and ethyl acetate (for liquid chromatography, $99.8 \%$ ) were purchased from Merck KGaA. 


\section{Methods}

The structure and adsorption parameters of $A C$ were determined from nitrogen adsorption-desorption isotherms at $77 \mathrm{~K}$. The isotherms were measured using Autosorb-1-MP (Quantachrome), with prior degassing at $473 \mathrm{~K}$ for 12 hours. The specific surface area $\left(S_{B E T}\right)$ was calculated using the Brunauer-Emmett-Teller (BET) equation. The volume of micropores $\left(V_{m i}\right)$ was determined using the $t$-method. The Density Function Theory (DFT) was used to calculate the pore volume distribution as a function of radius and pore radius $\left(R_{p}\right)$. The sorption volume $\left(V_{s}\right)$ of pores was determined by measuring the benzene adsorption in desiccator, elemental composition - by Prehlya and Dumas methods [13,14].

Qualitative and quantitative characterization of functional groups on the surface of AC samples was performed by the Böehm titration method [15].

The chemical state of nitrogen atoms on the surface of NCM samples was examined by X-rays photoelectron spectroscopy (XPS) on the instrument VG ESCA.

The catalytic activity of nanoporous carbon materials and enzyme catalase has been determined on a model reaction of benzoyl peroxide decomposition by Michaelis constants calculation.

Weighed portions of benzoyl peroxide (BP) were used to prepare solutions (ethyl acetate) with desired concentrations (from 1 to $10 \%$ ). The BP concentration in the product was determined by iodometric titration.

The kinetics of BP decomposition in non-aqueous media was studied by the volumetric method. The BP decomposition was performed in a thermostated cell with stirring. The temperature of the reaction mixture was measured with an accuracy of $\pm 0.5^{\circ} \mathrm{C}$, ambient temperature with accuracy of $\pm 1{ }^{\circ} \mathrm{C}$, the amount of gases released in the reaction, with an accuracy of $\pm 0.01 \mathrm{~mL}$. The released gas volume measurements were carried out for 120 minutes. Each experiment was performed using $10 \mathrm{~mL}$ of BP solution. Michaelis constant $\left(K_{m}, \mathrm{mM}\right)$ was used for quantitative assessment of catalytic activity and for the comparison of this value for carbon nanomaterials and their modified forms. Initial reaction velocity $\left(V_{o}\right)$ for different substrate concentrations was used to determine the Michaelis constant [16]. The affinity constant $\left(K_{a f}\right)$ (an inverse value to the Michaelis constant) was calculated to facilitate the perception of obtained data.

The linear correlation of the catalytic activity $(\mathrm{Y})$ expressed in terms of the $K_{m}$ on parameters $\left(\mathrm{X}_{\mathrm{n}}\right)$ of carbon nanomaterials was studied.

\section{Results and discussion}

In order to establish the factors that affect the catalytic activity of the carbon material in a chosen reaction, a series of NCM samples have been synthesized with different structural and sorption characteristics, surface chemistry, and the presence of heteroatom in the structure. It has been shown that sorption pore volume and specific surface area vary within the range of $0.50-0.90 \mathrm{~cm}^{3} / \mathrm{g}$ and $650-2140 \mathrm{~m}^{2} / \mathrm{g}$, respectively.

Considering the KAU type carbon as an example, it can be observed that it is a material of mixed porosity with a predominance of micropores, which is evident in the sample N-KAU (77.4\% micropores) (Figure 1). The oxidation of KAU type carbon material leads to an insignificant decrease in the number of micropores and a reduced surface area (Table 1). At the same time, impregnation of carbon with urea increases the fraction of micropores, and to a lesser extent the specific surface area, which can be explained by the different influence of urea and nitric acid on the AC modification. Impregnation with urea does not affect the microporous structure, while the interaction with the carbon matrix occurs in mesopores, part of them being converted into micropores. Nitric acid, in its turn, also oxidizes the surface of the micropores, thus reducing their surface.

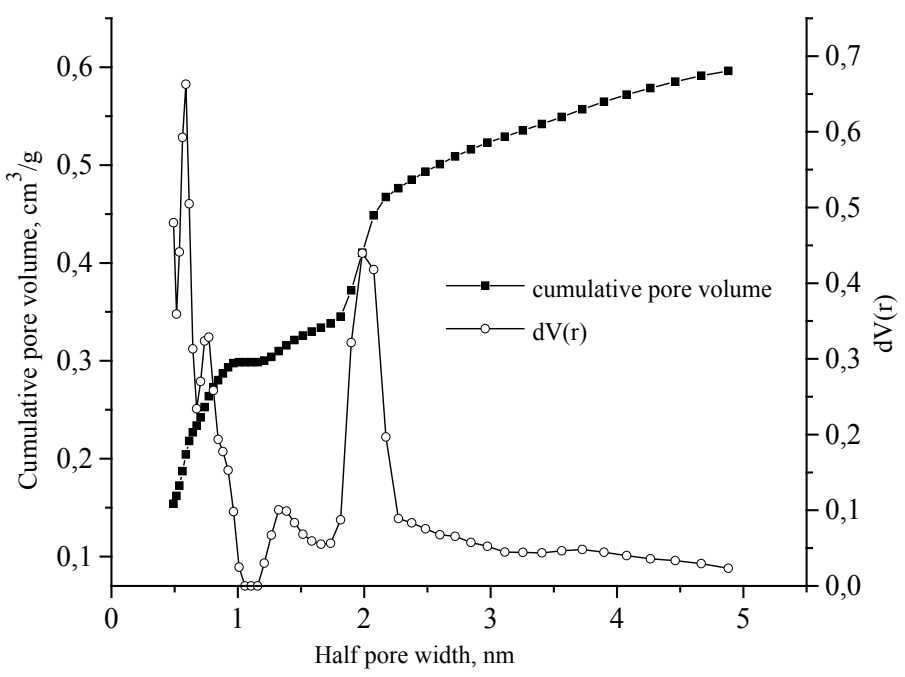

Figure 1. N-KAU pore size distributions by DFT method. 
Elemental analysis of carbon samples shows that during oxidation the number of oxygen atoms increases twice and 35-fold for SKN and activated carbon KAU, respectively. The increase in the number of hydrogen atoms suggests the formation of oxygen-containing functional groups on the SKN and KAU samples surfaces (Table 1). Titration results reveal that newly formed surface groups have a predominantly acid character. The total number of acidic groups increases during carbon oxidation by 18 and 20 times for SKN and KAU, respectively. Chemical immobilization of 1,5-pentanediamine on the surface of oxidized KAU leads to an almost 2-fold decrease of the total number of acid groups. Moreover, titration results show only the presence of phenolic groups on the AC surface.

Table 1

Structural and sorption characteristics, and elemental composition of studied samples.

\begin{tabular}{|c|c|c|c|c|c|c|c|c|}
\hline \multirow[b]{2}{*}{$N C M$} & \multicolumn{4}{|c|}{ Elemental composition, wt\% } & \multirow{2}{*}{$\begin{array}{c}V_{s} \\
\mathrm{~cm}^{3} / g \\
\left(X_{1}\right)\end{array}$} & \multirow{2}{*}{$\begin{array}{c}\text { Fraction } \\
\text { micropore } \\
\text { volume, } \\
\%\end{array}$} & \multirow[b]{2}{*}{$\begin{array}{l}R_{p} \\
n m\end{array}$} & \multirow{2}{*}{$\begin{array}{l}S_{B E T} \\
m^{2} / g \\
\left(X_{2}\right)\end{array}$} \\
\hline & $\mathrm{C}$ & $\mathrm{H}$ & $\begin{array}{c}\mathrm{O} \\
\left(X_{6}\right)\end{array}$ & $\begin{array}{c}\mathrm{N} \\
\left(X_{5}\right)\end{array}$ & & & & \\
\hline KAU & 99.40 & 0.20 & 0.06 & 0.30 & 0.50 & 55.0 & 0.58 & 920 \\
\hline KAUo & 96.30 & 1.10 & 2.10 & 0.60 & 0.85 & 53.8 & 0.57 & 790 \\
\hline N-KAU & 89.20 & 2.33 & 6.24 & 2.20 & 0.91 & 77.4 & 0.55 & 940 \\
\hline $\mathrm{KAUO}^{-\mathrm{NH}_{2}}$ & 78.60 & 1.98 & 16.80 & 3.30 & 0.56 & 66.7 & 0.73 & 650 \\
\hline SKN & 91.20 & 0.96 & 6.50 & 1.30 & 0.75 & n.d. ${ }^{*}$ & n.d. & 1970 \\
\hline SKNo & 85.80 & 0.90 & 11.20 & 2.00 & 0.80 & n.d. & n.d. & 2140 \\
\hline N-SKN & 91.25 & 1.20 & 3.70 & 3.85 & 0.84 & n.d. & n.d. & 1650 \\
\hline $\mathrm{R}^{2}$ & n.d. & n.d. & 0.01 & 0.13 & 0.34 & n.d. & n.d. & 0.01 \\
\hline
\end{tabular}

"n.d.- not determined

$V_{\text {s }}$ total pore volume

$R_{p}$ - pore radius

$S_{B E T}$-surface area determined by BET

Basic groups on samples surfaces were determined for SKN, N-SKN, N-KAU and KAUo-NH 2 (Table 2) in amounts ranging from 0.12 to $1.90 \mathrm{meq} / \mathrm{g}$, probably, due to the presence of nitrogen atoms in the structure of these materials. According to elemental analysis, the lowest nitrogen atoms content of $0.30 \%$ was found in the carbon KAU. The number of nitrogen atoms in AC structure increased twice as a result of oxidation by nitric acid, possibly because of carbon surface nitration processes. Functionalization of KAU allowed including nitrogen atoms up to $2.20 \%$. SKN contained nitrogen obtained from the vinylpyridine resin [17]. The total nitrogen content in the synthetic carbon SKN increased with oxidation, too. The highest nitrogen content of 3.85\% was achieved for the N-SKN carbon. It should be noted that the number of basic groups in the N-SKN activated carbon increased by 12 times compared to the initial material. The chemical immobilization of 1,5-pentanediamine on the surface of KAUo resulted in the appearance of basic groups associated with the presence of nitrogen in the structure, but their content was 8.6 times lower compared to the N-KAU.

Table 2

Functional groups on the surfaces of investigated samples.

\begin{tabular}{|c|c|c|c|c|c|}
\hline \multirow[b]{2}{*}{$N C M$} & \multicolumn{5}{|c|}{ Functional groups, meq/g } \\
\hline & carboxylic & lactonic & phenolic & $\begin{array}{c}\sum \text { of acidic } \\
\text { groups } \\
\left(X_{3}\right)\end{array}$ & $\begin{array}{c}\text { basic } \\
\text { groups } \\
\left(X_{4}\right)\end{array}$ \\
\hline KAU & 0.04 & 0.06 & 0.02 & 0.12 & 0.00 \\
\hline KAUo & 0.84 & 0.20 & 1.39 & 2.43 & 0.00 \\
\hline N-KAU & 0.00 & 0.45 & 0.05 & 0.50 & 1.90 \\
\hline KAUo-NH ${ }_{2}$ & 0.00 & 0.00 & 1.27 & 1.27 & 0.22 \\
\hline SKN & 0.08 & 0.02 & 0.02 & 0.12 & 0.12 \\
\hline SKNo & 1.04 & 0.10 & 1.01 & 2.15 & 0.00 \\
\hline N-SKN & 0.00 & 0.00 & 0.73 & 0.73 & 1.44 \\
\hline $\mathrm{R}^{2}$ & n.d. ${ }^{*}$ & n.d. & n.d. & 0.14 & 0.93 \\
\hline
\end{tabular}

${ }^{*}$ n.d.- not determined 
Analysis of the temperature-programmed desorption mass spectra of BP decomposition product showed that decomposition of 1 mole BP released 2 moles of gas that allowed performing quantitative determination of changes in BP concentration in time by the measurement of the released gas volume [18].

The catalytic activity of materials during the process of BP decomposition was experimentally determined (Figure 2). The coefficient of determination $\left(R^{2}\right)$ of calculated affinity constants and the Michaelis constant during an experiment was not lower than 0.85 .

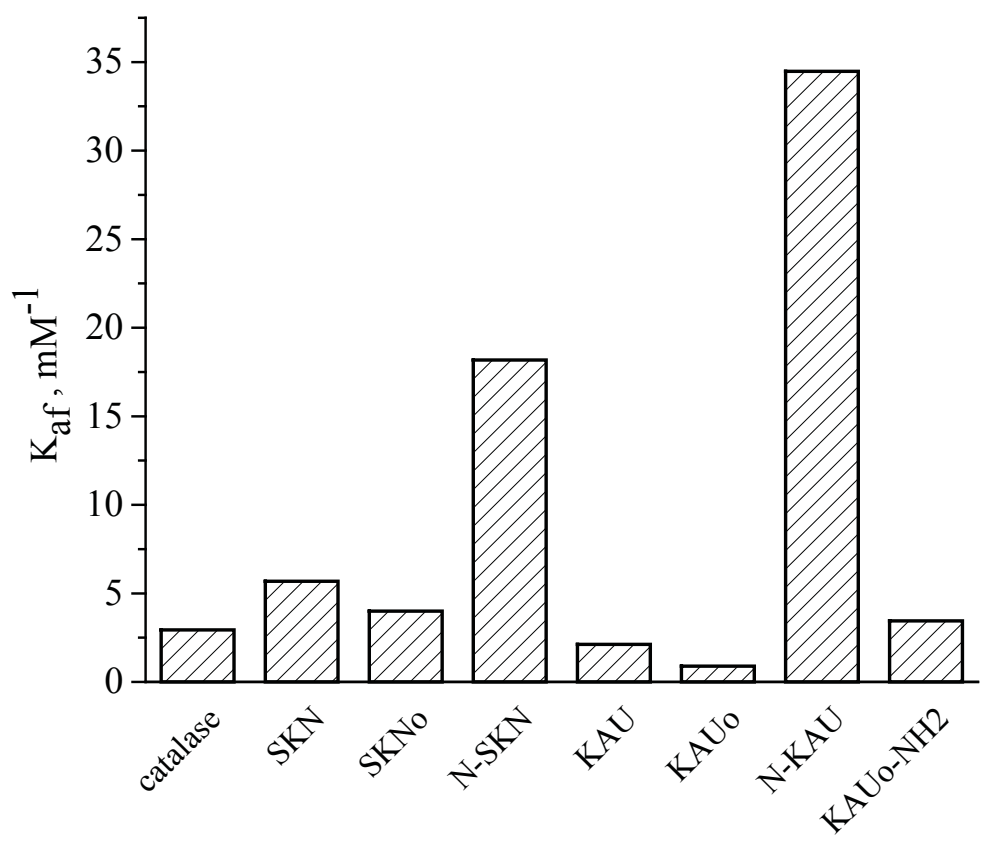

Figure 2. The catalytic activity of the investigated materials.

It was established that the catalytic activity of the investigated materials $\left(K_{a p}, \mathrm{mM}^{-1},(\mathrm{Y})\right)$ decreased in the following order: N-KAU (34.5) $>$ N-SKN (18.2) $>$ SKN (6.2) $>$ SKNo (4.0) $>$ catalase (3.7) $>\mathrm{KAUo}^{-N_{2}}$ (3.4) $>\mathrm{KAU}$ (2.1) > KAUo (0.9). The catalytic activity of nitrogen containing NCM was larger than that of enzyme catalase. Among all investigated materials the N-KAU showed the highest value. On the other hand, N-SKN showed a significant activity, 3 -folds higher than that of the initial SKN. The SKNo was characterized by less activity than other nitrogen-containing NCM. The KAUo- $\mathrm{NH}_{2}$ material was more active than KAU and KAUo, which had the lowest activities. Thus, nitrogencontaining materials provided higher catalytic activity than other NCMs, which could be explained by the fact that nitrogen as an electron-donating element provided a higher mobility of electrons in the carbon matrix and reduced the electron work function at the carbon/liquid or carbon/gas interfaces. Oxidation of carbon materials decreased their catalytic activity reducing the electron-donating ability which hindered the electron transport through the BP molecule. The catalytic activity of catalase in the BP decomposition process in non-aqueous media had an intermediate value between the nitrogen-containing NCM material $\mathrm{KAUo}-\mathrm{NH}_{2}$ and SKNo. This indicates that carbon nanomaterials can be used as biocatalysts in non-aqueous environment and under certain conditions to achieve a higher efficiency compared to enzymes.

Next, the factors influencing the catalase-like activity of investigated NCM in BP decomposition in nonaqueous media have been investigated. No correlation $\left(R^{2}\right)$ between catalytic activity $\left(K_{a f}, \mathrm{Y}\right)$ and structural factors $\left(\mathrm{X}_{1}\right.$ and $\left.\mathrm{X}_{2}\right)$ has been detected: $R_{1}{ }^{2}=0.34$ and $R_{2}{ }^{2}=0.01$, respectively (Table 1), indicating that those parameters are of secondary importance. The total content of surface acidic groups $\left(\mathrm{X}_{3}\right)$ and oxygen content $\left(\mathrm{X}_{6}\right)($ Table 2$)$ affects also the catalytic activity: $R_{3}^{2}=0.14$ and $R_{6}{ }^{2}=0.01$, respectively. At the same time, a correlation has been found between the presence of basic groups $\left(\mathrm{X}_{4}\right)$ and the catalytic activity: $R_{4}{ }^{2}=0.93$. It has been suggested that surface basicity is related to the presence of nitrogen-containing groups in the NCM structure. However, the catalytic activity is not correlated with the total nitrogen content $\left(\mathrm{X}_{5}\right) R_{5}{ }^{2}=0.13$. Probably, the catalytic activity of nitrogen-containing NCM depends on the chemical state of the nitrogen atoms, and not on the total nitrogen content in the structure.

The chemical state of nitrogen atoms and their relative content in the studied NCM was determined from the analysis of N 1s spectra XPS (Table 3). It was shown that the catalytic enzyme-like activity of carbon nanomaterials 
correlated with the presence of quaternary nitrogen through increasing electron-donating capacity of the carbon matrix. The higher activity of the modified nitrogen-containing NCM N-KAU and N-SKN compared to SKN could be attributed to the different content of quaternary nitrogen.

The obtained data are in agreement with the correlation between the activity and the basic groups on the NCM surface. Similar conclusions have been made in a published paper [19], where the authors showed that the presence of quaternary nitrogen increased the activity of $\mathrm{AC}$ in epoxidation of styrene and oxidative dehydrogenation of propane by increasing electron-donating of carbon atoms.

Table 3

The correlation between the chemical state of nitrogen and catalytic activity of NCM.

\begin{tabular}{|c|c|c|c|c|c|c|c|c|}
\hline \multirow{3}{*}{ Sample } & \multicolumn{7}{|c|}{ State of nitrogen atoms (relative content, \%) } & \multirow{3}{*}{$\begin{array}{c}K_{a \rho} \\
m M^{-1} \\
\\
Y\end{array}$} \\
\hline & $\begin{array}{c}\text { pyrroli- } \\
\text { donic }\end{array}$ & pyrrolic & pyridinic & $\begin{array}{l}\text { pyridine } \\
N \text {-oxide }\end{array}$ & $\begin{array}{l}\mathrm{NO}_{2}^{-} \\
\text {group }\end{array}$ & $C=N$ & quaternary & \\
\hline & \multicolumn{7}{|c|}{$X$} & \\
\hline KAU & 0.00 & 35.59 & 57.58 & 3.98 & 2.85 & 0.00 & 0.00 & 2.12 \\
\hline KAUo & 0.00 & 6.44 & 89.27 & 2.83 & 1.46 & 0.00 & 0.00 & 0.89 \\
\hline N-KAU & 0.00 & 1.12 & 67.38 & 0.00 & 4.09 & 14.18 & 13.23 & 34.48 \\
\hline $\mathrm{KAUO}_{\mathrm{NH}}$ & 35.93 & 0.00 & 60.67 & 1.30 & 0.00 & 0.00 & 2.10 & 3.44 \\
\hline SKN & 48.69 & 0.00 & 25.52 & 10.03 & 2.19 & 13.57 & 0.00 & 6.17 \\
\hline SKNo & 0.00 & 29.41 & 45.12 & 0.35 & 3.07 & 21.37 & 0.00 & 4.00 \\
\hline N-SKN & 0.00 & 0.00 & 64.45 & 2.39 & 0.23 & 32.39 & 0.54 & 18.18 \\
\hline $\mathrm{R}^{2}$ & 0.07 & 0.14 & 0.01 & 0.11 & 0.14 & 0.23 & 0.77 & \\
\hline
\end{tabular}

\section{Conclusions}

In this work the catalytic activity of carbon nanomaterials in a model reaction of benzoyl peroxide decomposition by Michaelis constants calculation, according to the kinetics of substrate decomposition, has been experimentally determined. A series of N-NCM prospective catalysts for organic peroxides decomposition in non-aqueous media have been synthesized. A number of carbon materials like KAU and SKN, their modified forms (oxidized, nitrogencontaining) and enzyme catalase have been tested. It has been shown that carbon materials exhibit an enzyme-like activity in non-aqueous media. It has been established that the catalytic ability of the samples does not correlate with the structural parameters but depends on their surface chemistry. The introduction of oxygen atoms decreases and nitrogen atoms increases the catalytic activity of the modified carbon nanomaterials. It has been shown that the enzyme-like catalytic activity of carbon nanomaterials correlates with the presence of quaternary nitrogen of the NCM.

\section{Acknowledgments}

This research was funded by the People Programme (Marie Curie Actions) of the European Union's Seventh Framework Programme FP7/2007-2013/ under REA, grant agreement No. PIRSESGA-2013-612484.

\section{References}

1. Xijun, H.; Lecheng, L.; Chu, H.P.; Yue L.P. Copper/activated carbon as catalysts for organic wastewater treatment. Carbon, 1999, 37, pp. 631-637.

2. Guo, B.; Chang, L.; Xie, K. Adsorption of Carbon Dioxide on Activated Carbon. Journal of Natural Gas Chemistry, 2006, 15, pp. 223-229.

3. Bagreev, A.; Bashkova, S.; Bandosz, T.J. Adsorption of $\mathrm{SO}_{2}$ on Activated Carbons: The Effect of Nitrogen Functionality and Pore Sizes. Langmuir, 2002, 18, pp. 1257-1264.

4. Attia, A.A.; Khedr, S.; Aelkholy, S.A. Adsorption of Chromium ion (VI) by acid Activated Carbon. Brazilian Journal of Chemical Engineering, 2010, 1, pp. 183 - 193.

5. Kadirvelu, K.; Faur-Brasquet, C.P.; Cloirec, L. Removal of $\mathrm{Cu}(\mathrm{II}), \mathrm{Pb}(\mathrm{II})$, and Ni(II) by Adsorption onto Activated Carbon Cloths. Langmuir, 2000, 16, pp. 8404-8409.

6. Hadi, P.; To, M.; Hui, C. Aqueous mercury adsorption by activated carbons. Water Research, 2015, 73, pp. 37-55.

7. Bautista-Toledo, I.; Ferro-Garcia, M.A.; Rivera-Utrilla, J. Bisphenol a Removal from Water by Activated Carbon. Effects of Carbon Characteristics and Solution Chemistry. Environmental Science and Technology, 2005, 39, pp. 6246-6250. 
8. Mahajan, O.P.; Moreno-Castilla, C.; Walker, P.L. Surface-Treated Activated Carbon for Removal of Phenol from Water. Separation science and technology, 1980, 15, pp. 1733-1752.

9. Urano, K.; Yamamoto, E.; Tonegawa, M.; Fujie, K. Adsorption of chlorinated organic compounds on activated carbon from water. Water Research, 1991, 25, pp. 1459-1464.

10. Ji, L.; Chen, W.; Duan, L.; Zhu, D. Mechanisms for strong adsorption of tetracycline to carbon nanotubes: A comparative study using activated carbon and graphite as adsorbents. Environmental Science and Technology, 2009, 43, pp. 2322-2327.

11. Fidalgo, B. Carbon materials as catalysts for decomposition and $\mathrm{CO}_{2}$ reforming of methane: a review. Chinese Journal of Catalysis, 2011, 32, pp. 207-216.

12. Zhuravsky, S.V.; Kartel, M.T.; Tarasenko, Yu.O.; Villar-Rodil, S.; Dobos, G.; Toth, A.; Tuscon, J.; Laszlo, K. $\mathrm{N}$-containing carbons from styrene-divinylbenzene copolymer by urea treatment. Applied Surface Science, 2012 , 258, pp. 2410-2415.

13. Klimova, V.A. Basic Micromethods of Organic Compounds Analysis. Moscow: Khimia, 1967, 208 p. (in Russian).

14. Alekseev, V.N. Quantitative Analysis. Moscow: Khimia, 1972, 504 p. (in Russian).

15. Boehm H.P. Surface oxides on carbon and their analysis: a critical assessment. Carbon, 2002, 40, pp. 145-149.

16. Glevatska, K.V.; Bakalinska. O.M.; Kartel, M.T. The study, description and comparison of catalase activity of carbon sorbents of SKN and KAU type. Scientific notes of NaUKMA, Chemical Science and Technology, 2008, 79, pp. 19-23 (in Ukrainian).

17. Strelko, V.V.; Nemoshkalenko, V.V.; Kartel, N.T.; Medvedev, S.L. On the state of the nitrogen atoms in the graphite lattice of activated carbons. Adsorption and Adsorbents, 1983, 11, pp. 76-80 (in Russian).

18. Haliarnik, D.M.; Bakalinska, O.M.; Palyanytsya, B.B.; Kulyk, T.V.; Kartel, M.T. Organic Peroxides Decomposition by Carbon Nanomaterials in Nonaqueous Media. Surface, 2015, 7(22), pp. 253-263 (in Ukrainian).

19. Podyacheva, O.Y.; Ismagilov, Z.R. Nitrogen-doped carbon nanomaterials: To the mechanism of growth, electrical conductivity and application in catalysis. Catalysis Today, 2014, 249, pp. 12-22. 